\title{
Artificial Intelligence in Building Information Modeling Research: Country and Document-based Citation and Bibliographic Coupling Analysis
}

\author{
Gozde Basak Ozturk ${ }^{1 *}$ and Mert Tunca ${ }^{2}$ \\ ${ }^{1,2}$ Aydın Adnan Menderes University, Civil Engineering Department, Aydın, Turkey \\ *gbozturk@adu.edu.tr \\ *Orcid No: 0000-0003-4617-6936
}

Received: 16 July 2020

Accepted:14 September 2020

DOI: 10.18466/cbayarfbe. 750565

\begin{abstract}
The intense association of the architecture, engineering, construction, operation, and facility management (AECO/FM) industry with cognitive and behavioral technologies leads to the increase in productivity of industry activities. In light of these thoughts, the building information modeling (BIM) platform is included in the AECO/FM industry to further increase efficiency and deliver construction projects economically, timely, and safely. While the BIM platform can work integrated with many programs and systems, concepts that offer innovative and fast solutions such as artificial intelligence (AI) benefit the AECO/FM industry. The main aim of this study is to establish an understanding of the tendency of AI in BIM research carried out in different countries and by various scholars. This study adopts a bibliometric search, and a scientometric analysis and mapping approach with applying document-based citation analysis, country-based citation analysis, and countrybased bibliographic coupling analysis of scientific research of AI and BIM integration. Data about AI in BIM research has been collected by reviewing and screening articles selected from the Scopus database. The results reveal that information management, decision support systems, genetic algorithms, neural networks, knowledgebased systems, machine learning, and deep learning effect AI in BIM research. This article contributes to the $\mathrm{AECO} / \mathrm{FM}$ literature by analyzing and visualizing the current status and relationship between AI and BIM. Therefore, the findings highlight the gaps and trends in AI and BIM studies and provide new recommendations for future studies.
\end{abstract}

Keywords: Artificial Intelligence (AI), Building Information Modelling (BIM), Scientometric Analysis, Scientometric Mapping

\section{Introduction}

Construction projects face many obstacles such as accidents in construction sites, unreliable complex schedule and cost planning, errors caused by inadequate planning, and lack of collaboration. Building information modeling (BIM) has been utilized in the architecture, engineering, construction, operation, and facility management (AECO/FM) industry to overcome these obstacles. BIM is a platform that adopts a very different design understanding and approach with the use of computer-aided technologies used in the AECO/FM industry. The construction project activities inevitably require BIM to be implemented or greater efficiency improvements and less cost and time lost throughout the project life cycle. A project lifecycle consists of a series of processes that a project goes through from its beginning to its closure. BIM has become more and more widely adopted day by day in the AECO/FM industry. As a result of this, it has begun to change the way the construction project delivered and the facility managed [1]. Thereby, the BIM platform provides fast solutions with the support of interoperability and management. Interoperability enables products, systems, or business processes to work together to carry out a common process [2]. However, to achieve accurate results, BIM requires a good work plan and regulations [3]. Therefore, the BIM platform must be integrated with new technologies such as artificial intelligence (AI), machine learning, the internet of things, and immersive technologies to provide more automated and faster solutions.

$\mathrm{AI}$ is a computer science that aims to adopt and apply like human thoughts, learning and perception 
capacities, and information storage abilities. AI is an important technology area that helps daily social life and activities and is directed towards the development of information communication technology (ICT) and robot technology (RT). AI creates rational agents that can perceive its environment and act to achieve goals. It develops in a predictable order and achieves its goals by performing analytical and intuitive movements. The tendency in AI research has increased since the mid-20th century, as it provided solutions and applied to a wide range of engineering and science problems. The performance of AI systems in deep learning stages can be used in the classification of big databases, visualization, explanation, and interpretation of their models. Probabilistic scientific data analysis, machine learning, and cognitive science, information theory which explains and interprets how to change the problems between these models, provide access to this area, and with this access, probabilistic programming, optimization, data compression, and automatic modeling occur.

Scientific data analysis is the process of analyzing, cleaning, transforming and modelling data with the aim of finding useful information, informing the results and supporting decision making. Machine learning is a science that deals with the design and development processes of algorithms that enable learning based on data types such as computer sensor data or databases. Cognitive science is an interdisciplinary approach that addresses the functioning of mind and intelligence and explores the dynamics and structures of intelligent systems. Probabilistic programming is a programming paradigm where probability models are specified, and inference is performed automatically for these models. Maximizing or minimizing some functions relative to a set represents a number of options available in a particular situation. Data compression is the process of changing, encoding or converting the bit structure of the data to take up less space. Automated model generation framework is used to identify three nonlinear dynamic benchmark processes. When big data is interpreted with the correct analysis methods, it can enable the strategic decisions to be taken correctly, to manage risk better, and to innovate. Data mining is the study of accessing useful information from large-scale data and mining information. Digital storage is a technology that consists of computer components and the recording medium is used to protect digital data. Data science is a multidisciplinary area that uses scientific methods, processes, algorithms, and systems to obtain information and insights from structured and unstructured data. Knowledge-based Engineering (KBE) can be defined as a program used to develop or query a knowledge base. Fuzzy
Logic (FL) is a method of reasoning that is similar to human reasoning. Artificial neural networks (ANN) are an information technology developed by inspiring the information processing technique of the human brain. Genetic algorithms (GE) are search and optimization methods that work in a similar way to the evolutionary process observed in nature and seek the best holistic solution according to the principle of survival of the best in complex multi-dimensional search space. A learning algorithm is a method used to process data to extract patterns appropriate for application in a new situation. In particular, the goal is to adopt a system to a specific input-output transformation task. Semantics is a linguistic and philosophical analysis of the meaning in language, programming languages, formal logic, and semiotics. Indicators relate to what they actually represent, such as words, phrases, signs, and symbols, and the relationship between their expressions.

Artificial intelligence use in the AECO/FM industry has been focused on increasing efficiency. Developing the construction process for decreasing project resources spent through effective planning via autonomous equipment that is aware of their surroundings is used for surveying, gathering site information to create maps, blueprints, and plans. $\mathrm{AI}$ also is used for monitoring and controlling tasks, choosing best alternatives, optimizing the processes and results, automation of systems and equipment $[4,5,10]$. AI and machine learning enhanced robots can also be used in dangerous and risky situations. IoT integrated systems offer a safer and efficient processes in both construction and operation of the facility.

The AECO/FM industry, which has experienced a radical revision with BIM adoption, has had the opportunity to integrate the above-mentioned new innovative solutions with utilizing AI. The digital data in a modeled project can be solved for AECO/FM industry by using computational research areas such as big data, data mining, digital storage, and data science. AI is available in $\mathrm{AECO} / \mathrm{FM}$ industry in project planning tools, building design analysis. It also includes tools of AI methods such as knowledge-based engineering (KBE), fuzzy logic (FL), neural networks, genetic algorithms, learning algorithms, and semantics. AI can provide fast results in many different designs and project submissions and can contain many alternative solutions. As a result of these alternatives, the processes of planning, construction, maintenance, and operation can be improved. The adaption of the AECO/FM industry to the digitalization era is late. However, can provide very effective solutions for the industry. The implementation of AI methods integration to 
the BIM platform for construction applications can provide benefits. In the light of the current literature, this article presents important research routes of $\mathrm{AI}$ in $\mathrm{BIM}$ research for the $\mathrm{AECO} / \mathrm{FM}$ industry, discussion of the latest trends, and suggestions for future studies. The integration of AI on the BIM platform has already been implementation areas in practical $\mathrm{AECO} / \mathrm{FM}$ industry activities such as Internet of Things (IoT) integration [6], Historical Building Information Modeling (HBIM) [7], smart energy systems [8], safety, decision support systems [9] and so many others [10].

\section{Methodology}

In this article, the tendency of AI use in BIM research that was carried out in different countries and by various scholars in the AECO/FM industry was investigated to put forth an overview and understanding by using bibliometric search, scientometric analysis and mapping. The selection of bibliometric search and scientometric analysis and mapping method was made in order to scientifically prove the results based on natural language processing of data from articles gathered by the bibliometric search to be utilized in scientometric analysis and mapping which allowed to empirically analyze the related literature data. The scientometric analysis was done via the document-based citation analysis, country-based citation analysis, and country-based bibliographic coupling analysis. The bibliometric search should be done in one database since there is no any tool to robustly combine the data that is retrieved from more than one database. Therefore, bibliometric search of publications of AI and BIM was performed in Scopus, one of the main search engines for academic research outputs. There are also other established, comprehensive, inclusive, and well-accepted databases. However, the Scopus database covers more journals and more publications than other sources [11]. Scopus uses an API search system that combines keywords with operators to refine the search for getting consolidated and relevant results by using Boolean Syntax. Scientometric mapping is a part of a scientometric analysis that evaluates research policies and processes by using bibliometric data [12]. Scientometric mapping is used to display a research domain's dynamic and structural aspects by defining the relationships among disciplines, fields, and papers [13]. VOSviewer is a tool that is used for visualizing large networks via natural language processing algorithms and text mining techniques and is a commonly used tool in scientometric analysis [14]. This research involves a scientometric mapping and analysis based on bibliometric data obtained by clustering and sequencing combinations of items such as documents and countries. It visualizes, computes, analyzes and explores the AI in BIM research area in the context of the AECO/FM industry. Bibliometric search was applied using the Boolean Syntax with combining words mentioned in Figure 1 via the Scopus database. As a result of this research, 199 results have been reached. Further limitations such as English language and scientific research field restrictions were applied, and the number of files decreased to 195 .

\{artificial intelligence\} OR \{AI\} AND \{building information modelling\} OR \{building information modeling OR \{BIM \} OR \{building information model\} (LIMIT-TO (LANGUAGE, "English")) AND (LIMIT-TO (SUBJAREA, "ENGI") OR LIMIT-TO (SUBJAREA, "COMP") OR LIMIT-TO (SUBJAREA, "SOCI") OR LIMIT-TO (SUBJAREA, "BUSI") OR LIMIT-TO (SUBJAREA, "ENER") OR LIMIT-TO (SUBJAREA, "ENVI") OR LIMIT-TO (SUBJAREA, "DECI") OR LIMIT-TO (SUBJAREA, "MATE" ) OR LIMIT-TO (SUBJAREA, "ARTS") OR LIMIT-TO (SUBJAREA, "MULT"))

Figure 1. Bibliometric search input

The VOSviewer software was developed to generate and display scientific measurement results and maps by utilizing natural language processing algorithms based on keyword, journal, author, and document data. In this research, the VOSviewer software was used to analyze and calculate Scopus data using for AI in BIM research. Country-based citation analysis was done to reveal the links of the countries in which the articles were prepared. The minimum number of documents of a country was set to 5 , and the minimum number of citations of a country was set to 1 . The threshold was reached by 13 countries out of 41 . Country-based bibliographic coupling analysis was performed to indicate common references in articles of countries. The minimum number of documents of a country was determined as 5, and the minimum number of citations of a country was set to 1 . The threshold was reached by 13 countries out of 41 . Documentbased citation analysis was done for published 
articles and trends of the articles and their belonged cluster was determined. The minimum number of citations of a document was determined as 19 The threshold met by 12 documents out of 185 . A network of items was established in VOSviewer by natural language processing algorithms to explore the relationship between them and to organize the knowledge by using clustering methods [15]. The items were clustered by VOS clustering technique and color-coded in Figures 2, 3 , and 4. The color of an item symbolizes the cluster to which it belongs. The clusters are presented in Tables alongside their constituent items (country, document). There can only be one link between two items. The strength of a link is denoted by a positive value. The lower the strength, the weaker the link; the higher the strength, the stronger the link. The strength of a link represents the number of papers in which two items occur together. The meanings of the column headings in Tables are explained below.

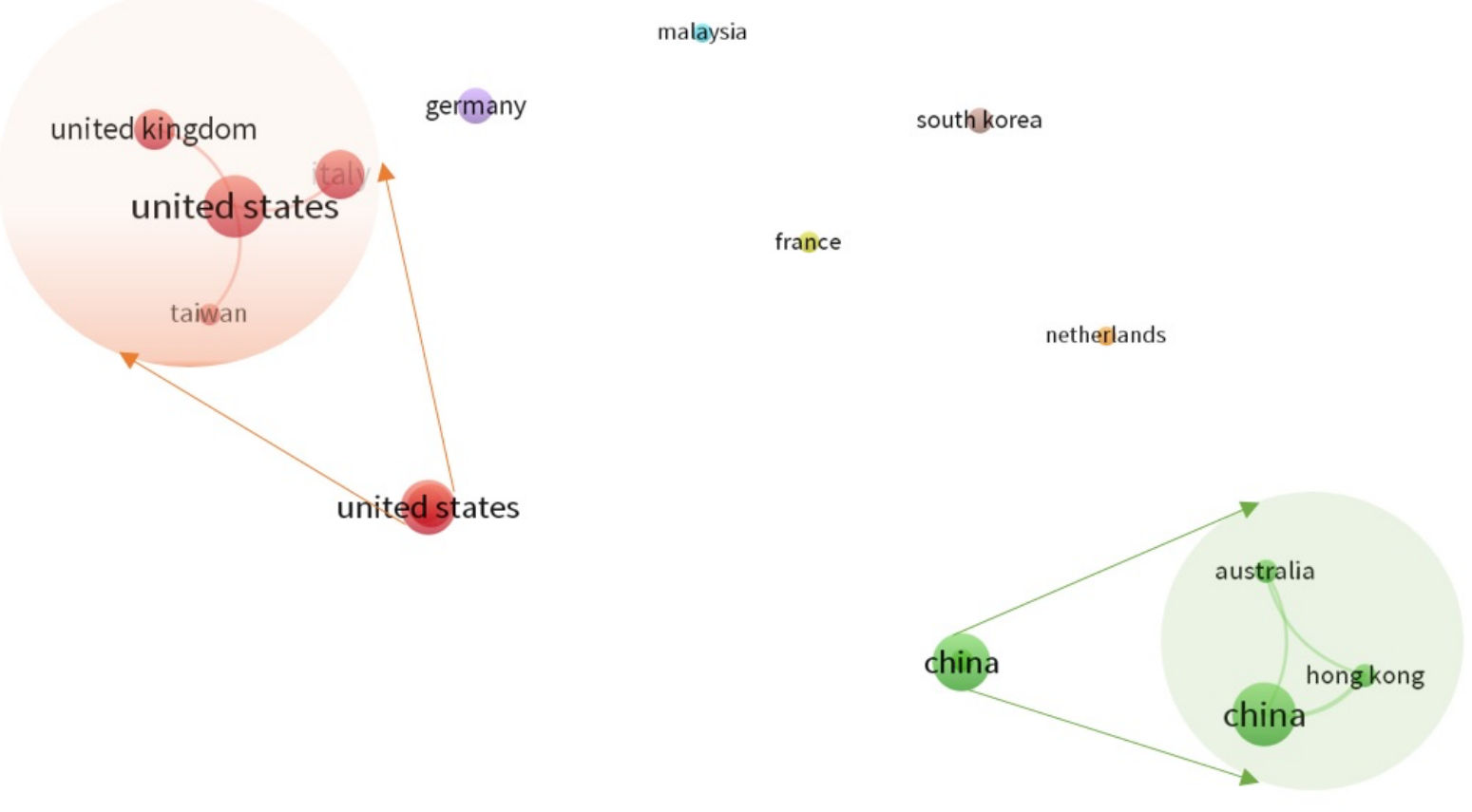

Figure 2. Network visualization map of the country-based citation analysis of AI in BIM research (detailed visual representation of linked countries was zoomed in).

- The number of links between a keyword and other keywords represents the relatedness between the keywords.

- Total link strength demonstrates the strength of the relationship between keywords.

- Average publication year of the papers in which a keyword occurs displays the chronology of a keyword's appearance in the related literature. The more recent the average year published, the newer the keyword is and so is the research subject.

- Average citation represents the total number of citations received by all the papers in which a keyword occurs, divided by the number of papers in which this keyword occurs.
- Average normalized citation indicates the average of the normalized citation for all documents in the set. Normalized citation is calculated by dividing the total number of citations of a paper by the number of citations of papers of the same type. The higher the average normalized citation, the higher the impact on the literature.

\section{Findings}

\subsection{Results of The Country-Based Citation Analysis}

The use of AI and BIM together is an approach that is constantly developing with research in different countries. The citation analysis has been made to show the country-based effect on the literature that presents in Figure 2 via VOSviewer, and the scientometric map achieved as a result of the 
scientometric analysis. As a result of the analysis, 8 clusters have occurred. Each of the clusters has been shown in a different color. The links among circles, colors, and distance represent the relationship between the country pairs. From these clusters, it is seen that red and green are connected within themselves, while other clusters are separate and distant from each other. The data obtained as a result of the analysis are listed in Table 1 . The three countries that publish the most on 'AI in BIM research' are China, the United States, and Italy. Total link strength shows the strength of a countrybased research link with other countries. The three highest total link strength valued countries are respectively, the United States, China, and Hong Kong. When the researches of the three countries are examined, it can be seen that modern technology tools are utilized such as computers and sensors, learning systems, information management, automation, and semantic.

Table 1. The country-based citation analysis of AI in BIM research.

\begin{tabular}{|c|c|c|c|c|c|c|}
\hline Cluster & Link & $\begin{array}{l}\text { Total Link } \\
\text { Strength }\end{array}$ & $\begin{array}{l}\text { Document } \\
\text { Numbers }\end{array}$ & $\begin{array}{l}\text { Average } \\
\text { Publication } \\
\text { Year }\end{array}$ & $\begin{array}{l}\text { Average } \\
\text { Citations }\end{array}$ & $\begin{array}{l}\text { Average } \\
\text { Normalized } \\
\text { Citations } \\
\end{array}$ \\
\hline \multicolumn{7}{|c|}{ Research Region 1} \\
\hline Italy & 1 & 1 & 19 & 2017.68 & 5.16 & 1.26 \\
\hline Taiwan & 1 & 1 & 5 & 2018.20 & 0.20 & 0.11 \\
\hline United Kingdom & 1 & 1 & 14 & 2016.86 & 5.29 & 1.17 \\
\hline United States & 3 & 3 & 28 & 2015.68 & 11.68 & 1.41 \\
\hline \multicolumn{7}{|c|}{ Research Region 2} \\
\hline Australia & 2 & 2 & 6 & 2017.00 & 6.67 & 5.61 \\
\hline China & 2 & 3 & 30 & 2016.53 & 7.93 & 1.17 \\
\hline Hong Kong & 2 & 3 & 6 & 2014.50 & 32.00 & 2.61 \\
\hline \multicolumn{7}{|c|}{ Research Region 3} \\
\hline Canada & 0 & 0 & 12 & 2016.42 & 4.75 & 0.73 \\
\hline \multicolumn{7}{|c|}{ Research Region 4} \\
\hline France & 0 & 0 & 7 & 2015.71 & 3.43 & 0.54 \\
\hline \multicolumn{7}{|c|}{ Research Region 5} \\
\hline Germany & 0 & 0 & 15 & 2015.47 & 8.47 & 1.86 \\
\hline \multicolumn{7}{|c|}{ Research Region 6} \\
\hline Malaysia & 0 & 0 & 5 & 2014.40 & 9.00 & 1.49 \\
\hline \multicolumn{7}{|c|}{ Research Region 7} \\
\hline Netherlands & 0 & 0 & 5 & 2015.60 & 1.20 & 0.20 \\
\hline \multicolumn{7}{|c|}{ Research Region 8} \\
\hline South Korea & 0 & 0 & 8 & 2014.88 & 5.62 & 0.58 \\
\hline
\end{tabular}

3.2. Results of the country-based bibliographic coupling analysis

The bibliographic coupling demonstrates the conflict in the reference lists. If there is a common citation in both articles, these two articles are bibliographically related. The common reference number of the two articles reflects the strength of the bibliographic match relationship between articles. In this section, bibliographic matching analysis of the countries was applied to see the bibliographic matching relations of the countries. As a result of the analysis, the network visualization map was produced (Figure 3 ). As seen in the analysis the 3 different colors shown on the map represent the 3 clusters formed. The links and distance between circles represent publishing relations between country couples. The data obtained as a result of country-based bibliographic coupling analysis are listed in Table 2 . The total link strength value indicates the strength of the publication relationship between the two countries. The three countries with the highest total link strength value are the China, Germany, and the United Kingdom. Looking at the three most publishing countries are China, United States and Italy, respectively. 


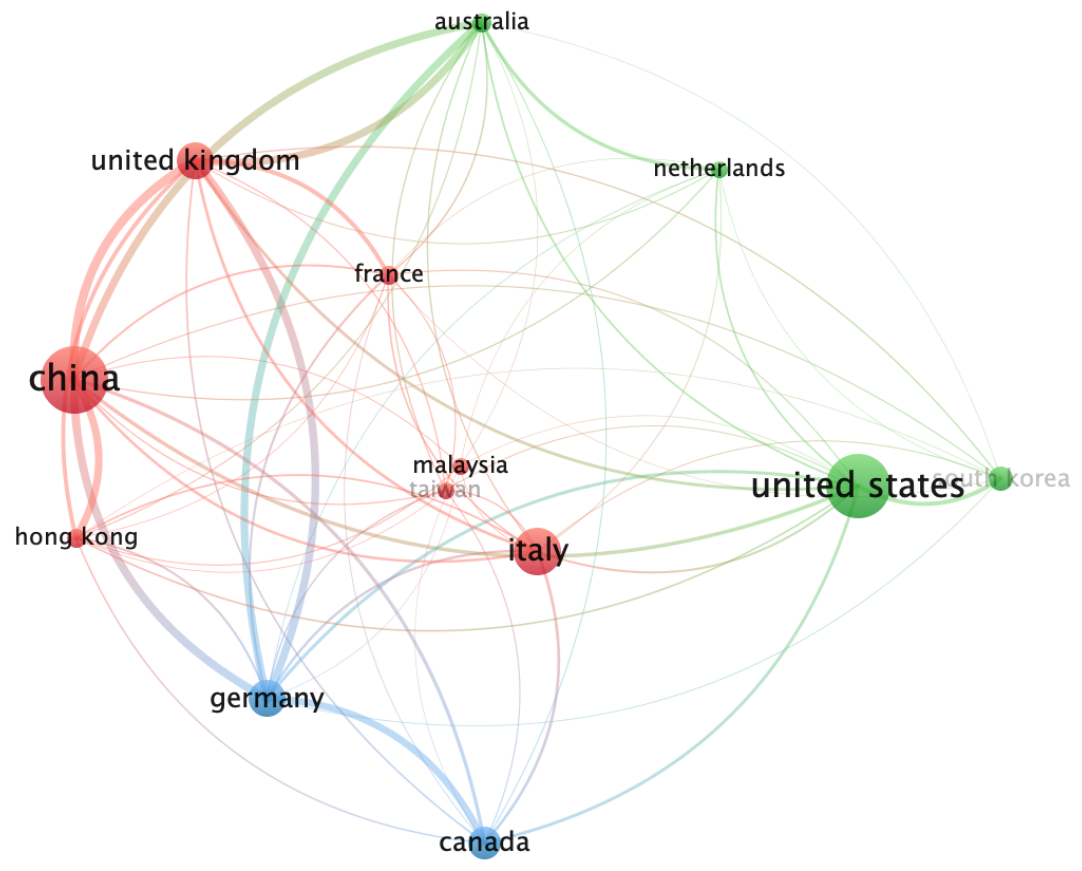

Figure 3. Network visualization map of the country-based bibliographic coupling analysis of AI in BIM research.

Table 2. The country-based bibliographic coupling analysis of AI in BIM research.

\begin{tabular}{|c|c|c|c|c|c|c|}
\hline Cluster & Link & $\begin{array}{l}\text { Total Link } \\
\text { Strength }\end{array}$ & $\begin{array}{l}\text { Document } \\
\text { Numbers }\end{array}$ & $\begin{array}{l}\text { Average } \\
\text { Publication } \\
\text { Year }\end{array}$ & $\begin{array}{l}\text { Average } \\
\text { Citations }\end{array}$ & $\begin{array}{l}\text { Average } \\
\text { Normalized } \\
\text { Citations } \\
\end{array}$ \\
\hline \multicolumn{7}{|c|}{ Research Region 1} \\
\hline China & 12 & 903 & 30 & 2016.53 & 7.93 & 1.17 \\
\hline France & 11 & 114 & 7 & 2015.71 & 3.43 & 0.54 \\
\hline Hong Kong & 11 & 272 & 6 & 2014.50 & 32.00 & 2.61 \\
\hline Italy & 12 & 139 & 19 & 2017.68 & 5.16 & 1.26 \\
\hline Malaysia & 9 & 17 & 5 & 2014.40 & 9.00 & 1.49 \\
\hline Taiwan & 10 & 44 & 5 & 2018.20 & 0.20 & 0.11 \\
\hline United Kingdom & 11 & 764 & 14 & 2016.86 & 5.29 & 1.17 \\
\hline \multicolumn{7}{|c|}{ Research Region 2} \\
\hline Australia & 12 & 589 & 6 & 2017.00 & 6.67 & 5.61 \\
\hline Netherlands & 9 & 61 & 5 & 2015.60 & 1.20 & 0.20 \\
\hline South Korea & 9 & 73 & 8 & 2014.88 & 5.62 & 0.58 \\
\hline United States & 12 & 229 & 28 & 2015.68 & 11.68 & 1.41 \\
\hline \multicolumn{7}{|c|}{ Research Region 3} \\
\hline Canada & 10 & 257 & 12 & 2016.42 & 4.75 & 0.73 \\
\hline Germany & 12 & 786 & 15 & 2015.47 & 8.47 & 1.86 \\
\hline
\end{tabular}

\subsection{Results of the documents-based citation analysis}

The network visualization map was obtained from document-based citation analysis of AI in BIM research, Figure 4 presents the image from the VOSviewer. The lines, colors, and distance between circles show the relationship between the documents' mutual quotes and document pairs. The size of the circle and the fonts show additive of the document to the research area. The large circle reflects that the document contributes more to the research topic. The link, citation, normalized citation and publication year data obtained as a result of the document-based citation analysis are shown in Table 3. The link values represent interconnected articles. The number of citations explains results of the number of times the article was cited as a source in documents to be published by an author. In Table 3 , the 12 documents revealed in the analysis are interconnected. The three most cited documents are "Golparvar-Fard et al., 2015" [21], "Chen et al., 2015" [20], and "Teizer, 2015" [27] (Fig. 3 and Table 3).

Golparvar-Fard et al. [21] investigates automated progress monitoring using unordered daily construction photographs and Industry Foundation 
Classes-based (IFC-based) building information models. This study shows a new automated understanding of the recognition of physical progress according to the two main sources of information that have emerged. The first is unordered daily construction photo data, collected almost free of charge at all available construction sites. The second is the BIM designs, which are increasingly becoming the binding components of architectural, engineering and construction contracts.

Chen et al. [20] investigates the relation between bridging BIM and building and provides a conceptual structure for bridging the BIM and the building, which emphasizes the importance of reallife information synchronization. The prepared structure is presented in more detail with the prefabricated residential construction in Hong Kong.

Teizer [27] studies the status quo and open challenges in vision-based sensing and tracking of temporary resources on infrastructure construction sites. This study provides an overview of the vision-based sensing technology available for resource monitoring in infrastructure construction sites. Second, it provides research applications by highlighting the case study. Third, it opens a discussion about the current advantages and limitations of visual perception and monitoring.

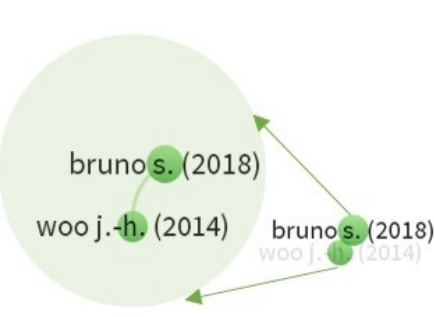

zhang je. (2017)

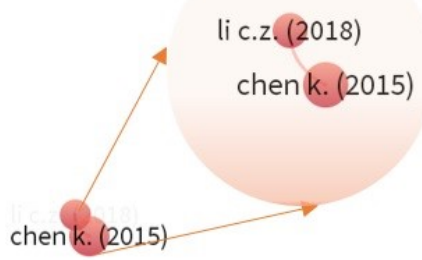

huangy. (2008)

teizerj. (2015) jalaei f.(2015) golparvar-fard m. (2015) kim j.i. (2015)

tixier a.j.-p. (2016)

memon a.h. (2014)

Figure 4. Network visualization map of the document-based citation analysis of AI in BIM research.

Table 3. The document-based citation analysis of AI in BIM research.

\begin{tabular}{lcccc}
\hline Documents & Link & Citation & $\begin{array}{l}\text { Normalized } \\
\text { Citation }\end{array}$ & $\begin{array}{l}\text { Publication } \\
\text { Year }\end{array}$ \\
\hline Bruno et al., 2018 [31] & 1 & 41 & 7.88 & 2018 \\
Chen et al., 2015 [32] & 1 & 81 & 3.03 & 2015 \\
Golparvar-Fard et al., 2015 [33] & 0 & 117 & 4.37 & 2015 \\
Huang et al., 2008 [34] & 0 & 40 & 1.67 & 2008 \\
Jalaei et al., 2015 [35] & 0 & 21 & 0.78 & 2015 \\
Kim et al., 2015 [36] & 0 & 24 & 0.90 & 2015 \\
Li et al., 2018 [37] & 1 & 42 & 8.07 & 2018 \\
Memon et al., 2014 [38] & 0 & 33 & 4.12 & 2014 \\
Teizer, 2015 [39] & 0 & 59 & 2.20 & 2015 \\
Tixier et al., 2016 [40] & 0 & 47 & 7.66 & 2016 \\
Woo et al., 2014 [41] & 1 & 26 & 3.25 & 2014 \\
Zhang et al., 2017 [42] & 0 & 21 & 6.52 & 2017 \\
\hline
\end{tabular}




\section{Discussions}

BIM model development and intervention require multiple software use and integration. Considered as a platform, the BIM model requires enhanced systems integration for the AECO/FM industry. Research study on AI in BIM research attracts many researchers as it will be seen as an important factor in the faster adoption of BIM in the $\mathrm{AECO} / \mathrm{FM}$ industry. As the use of BIM in the $\mathrm{AECO} / \mathrm{FM}$ industry becomes more common, advances in BIM model technology have increased rapidly due to the needs of stakeholders and consequently, concepts such as AI are included.

BIM research focuses mostly on computer-aided design today. It is extremely important in the $\mathrm{AECO} / \mathrm{FM}$ industry that the BIM model now moves from a 3D information database to an $\mathrm{nD}$ multi-information platform. With this importance, it is thought to produce solutions in managementbased studies in the AECO/FM industry since construction management has recently used cognitive technologies in construction project processes. The integration of the BIM model and AI solutions becomes particularly interesting in project management. BIM model integration with real-world instantaneous building data increases the use of model information throughout the life cycle of projects. That is why the BIM model and building information integration can be realized through the AI integration such as using Internet of Things (IoT) sensors.

Information processing and information technology studies on AI integration via interoperability are prioritized in BIM research [11]. In order to integrate the BIM model with metadata that can be interpreted by machine learning, semantic web technology development studies are carried out for use in information management and facility management. As a result of these integrability developments, GIS integration has been provided

and widely used in the BIM model together with deep learning systems. With the developed models, information was used with electronic data exchange tools and the use of information for decisionmaking systems was at the focal point of recent researches. In addition, thanks to the building automation provided by the AI integrated systems of the BIM model, efforts are made to increase energy efficiency and sustainable that smart building designs that streamline energy use have been frequently encountered in the literature recently [16]..

\subsection{Discussions of the country-based citation analysis}

Many countries attach importance to studies on AI adaptation and increase their study day by day. The $\mathrm{AECO} / \mathrm{FM}$ industry is also affected by this increasing trend in recent years. The two countries with the most research were China and the United States. These countries are followed by Italy, Germany, United Kingdom and Canada respectively. South Korea, France, Australia, Hong Kong, Taiwan, Malaysia, and Netherlands follow countries with less research studies than other countries. Especially, the use of information management and decision-making and implementation systems show that countries have begun to develop sustainable methods. New methods, such as semantics and automation, can be a potential to remain permanently for AI utilization in the AECO/FM industry. Countries' study on AI in BIM research contributes to both economic development and sustainable building cycles. It is thought that new methods of using and developing technology so closely can create new conveniences and opportunities in the AECO/FM industry $[17$, 18]. Since BIM and AI integration is a new and hot topic, the scarcity of studies on their use together is remarkable. The papers within this research's sample were examined in detail and it was seen that new technological methods are used in only a few studies in some countries. The topics that are beginning to be the new trend in the countries are data mining and digital storage. In these studies, methods such as learning systems were used as technological tools. The lack of studies in these areas causes an important gap in the literature. AI and multiple technologies together can be integrated into the BIM platform to achieve sustainability in the AECO/FM industry.

\subsection{Discussions of the country-based bibliographic coupling analysis}

Countries have started to study various subjects in this area for many different purposes. It is discovered that AI can provide potential benefits in different disciplines within the industry in order to make the project and construction management processes more efficient [4]. For example, there may be many more advantages such as direct prevention of cost overruns, better-designed buildings, and minimizing risk. Countries often introduce new studies by benefiting from each other's work and by making use of joint studies in bibliographic matching. The fact that most countries have little research on AI in BIM research which, shows how hot and promising the topic is in the literature. The leading countries in this regard are China and the United States. The countries that 
follow these two countries with their artificial intelligence studies and are in the development stages are Italy, Germany, United Kingdom and Canada. South Korea, France, Australia, Hong Kong, Taiwan, Malaysia, and the Netherlands are the countries that have fewer research studies in this field compared to other countries. When the studies are examined in detail, it can be seen from the links that countries proceed with by publishing together or citing each other's articles. There are not many publications yet about approaches to BIM and AI integration. New job opportunities can be created because there is little implementation on this subject. In this sense, the use of highly critical technologies such as $\mathrm{AI}$ within the $\mathrm{AECO} / \mathrm{FM}$ industry demonstrates the fact that it may enable sustainability in construction in the future by influencing the change in the processes, techniques, equipment, and work routines.

\subsection{Discussions of the document-based citation analysis}

The fact that technology is a constantly and rapidly improving scientific research branch, it has led to the emergence of many specialties and disciplines in the $\mathrm{AECO} / \mathrm{FM}$ industry. AI individually contributed to the research in construction $[4,5,6$, $7,8,9,10,16,17,18]$. The papers within this research's sample were in detail, the influential articles contain subjects such as information management, information technologies, and semantics. Since there are a lot of complex information and data, it becomes obvious that AI should be on the focus of researchers for the improvements in the industry. Studies focus on big data, digital storage and IFC as a result of the need for data flow and storage needs. In addition, there are many application areas that are practiced and preferred in the industry namely; preventing cost exceed, minimizing risk, operations and facility management, and energy performance estimation $[5,6,7,8,9,10,16,17,18]$. The study of the different specialties and disciplines is accepted to be independent of each other in groups. Integration into the BIM platform is a new phenomenon, as AI is a broad area. Therefore, it makes it difficult for $\mathrm{AI}$ to be examined as a whole in the AECO/FM industry as part of the BIM technology.

\subsection{Gaps and trends}

Integrated use of BIM and AI is still a very new and hot topic. Information management and decision support systems are the subjects where BIM and AI studied intensively. In this process, data are collected by obtaining different opinions from many specialties such as architecture, engineering, and computer science. Studies resulting from the collection of data generate complex information and independent from each other. These complexities and problems can be avoided and can be collected and processed in a single environment by using AI. Providing a common space with BIM to work together can help to resolve information clutter. The information obtained can be modeled at the $\mathrm{nD}$ level using the BIM platform. AI can prevent time loss and ensure complete storage of information. Computer science, which offers great potential for integrated solutions, is used in some countries very effectively such as in the USA and China. These two countries are followed by Italy, Germany, England and Canada with their constantly developing works. Also, although South Korea, France, Australia, Hong Kong, Taiwan, Malaysia and the Netherlands have fewer research studies than other countries, their future work is expected to increase. The study contributes to the $\mathrm{AECO} / \mathrm{FM}$ industry literature by analyzing and visualizing the current situation of AI in BIM research.

\section{Conclusion}

In this study, it is aimed to reveal the scientific tendency related to the AI in BIM research and to explain the research orientation in different countries. Combining and developing AI and BIM research areas reduces cost, time, and increases productivity [16]. Therefore, a scientometric analysis and mapping of bibliometric data have been done by country-based citation analysis, document-based citation analysis, and countrybased bibliographic coupling analysis thanks to VOSviewer software. As seen in the analysis of the countries, 8 regions were revealed. There are 12 documents found as the result of document-based citation analysis. The analysis revealed that interconnected documents study in similar areas and 8 independent documents contain publications from different specialties. The idea of the integrated operation of BIM and $\mathrm{AI}$ is the idea of creating intelligent systems that can help learn and solve problems quickly. In the AECO/FM industry, AI provides advantages to deal with complex engineering, management, and implementation issues, unlike solutions based on traditional computing and design methods $[4,5,6,7,8,9,10$, $16,17,18]$. As a result of these advantages, it aims to solve many problems faster by integrating into the BIM platform throughout the design, construction, operation, and facility management processes throughout the project life cycle. In many countries, mainly China, the USA, and Italy actively use BIM and AI with a processable structure. It has been observed that it increases productivity and efficiency, especially in information management and decision-making 
system organization. As seen in the documentbased citation analysis independent examination of the research fields makes it difficult to examine the studies with a holistic view. Apart from being a new and hot topic, the complexity of the wide range of research areas and scarcity of studies in the field can create difficulties. However, in the future, the use of technology platforms for integration in BIM and $\mathrm{AI}$ processes can ensure the interoperable information management systems used for different areas of expertise and benefit from the study of different perspectives can yield efficiency. Although the high contribution of this study to figure out the research tendency in different countries, it has limitations such as the time period of the data acquisition causes a static output, further analysis need, the Scopus' coverage of all publications, and so on. The findings of this research provide a broad understanding of the current research approach, research gaps, and future research trends of $\mathrm{AI}$ in $\mathrm{BIM}$ research for the $\mathrm{AECO} / \mathrm{FM}$ industry.

\section{Author's Contributions}

Gozde Basak Ozturk: Drafted and wrote the manuscript, performed the analyses, and result interpretation.

Mert Tunca: Drafted and wrote the manuscript, performed the analyses, and result interpretation.

\section{Ethics}

There are no ethical issues after the publication of this manuscript.

\section{References}

1. Liu Z, Lu Y, Peh L C (2019) A review and scientometric analysis of Global Building Information Modeling (BIM) Research in the Architecture, Engineering and Construction (AEC) industry. Buildings, 9, 10 DOI: 10.3390/buildings9100210.

2. Ganzha M, Paprzycki M, Pawłowski W, Szmeja P, Wasielewska K (2017) Semantic interoperability in the Internet of Things: An overview from the INTER-IoT perspective. Journal of Network and Computer Applications, 81, 111-124 DOI: 10.1016/j.jnca.2016.08.007.

3. Aljobaly O, Banawi A (2020) Evaluation of the Saudi Construction Industry for Adoption of Building Information Modelling. Advances in Artificial Intelligence, Software and Systems Engineering. 488-498 DOI: 10.1007/978-3-03020454-9 49

4. Parveen, R. (2018). Artificial intelligence in construction industry: Legal issues and regulatory challenges. International Journal of Civil Engineering and Technology, 9(13), 957-962.

5. Guzmán, J.I. And Malcolm, A.A. (2002) "Autonomous vehicles in the construction process", Construction
Innovation, Vol. 2 Issue: 3, pp.211- 224, https://doi.org/10.1108/14714170210814775.

6. Li, C. Z., Xue, F., Li, X., Hong, J., and Shen, G. Q. (2018). An internet of things-enabled BIM platform for on-site assembly services in prefabricated construction. Automation in Construction, $89, \quad 146-161$. doi:10.1016/j.autcon.2018.01.001.

7. Bruno, S., De Fino, M., and Fatiguso, F. (2018). Historic building information modelling: Performance assessment for diagnosis-aided information modelling and management. Automation in Construction, 86, 256-276. doi:10.1016/j.autcon.2017.11.009.

8. O'Dwyer, E., Pan, I., Acha, S., and Shah, N. (2019). Smart energy systems for sustainable smart cities: Current developments, trends and future directions. Applied Energy, 237, 581-597. doi:10.1016/j.apenergy.2019.01.024.

9. Hwang, B., Shan, M., and Looi, K. (2018). Knowledgebased decision support system for prefabricated prefinished volumetric construction. Automation in Construction, 94 , 168-178. doi:10.1016/j.autcon.2018.06.016.

10. Sacks, R., Girolami, M., Brilakis, I. (2020). Building Information Modelling, Artificial Intelligence and Construction Tech, Developments in the Built Environment, 100011, ISSN 2666-1659, https://doi.org/10.1016/j.dibe.2020.100011.

11. Ozturk, G.B. Interoperability in building information modeling for AECO/FM industry. Automation in Construction, 2020, 113, 103122. https://doi.org/10.1016/j.autcon.2020.103122.

12. $\mathrm{Xu}, \mathrm{Y}$.; Zeng, J.; Chen, W.; Jin, R.; Li, B.; and Pan, Z. (2018). "A holistic review of cement composites reinforced with graphene oxide", Construction Building Materials, Vol. 171, pp.291-302. doi.org/10.1016/j.conbuildmat.2018.03.147.

13. Cobo, M.J.; López-Herrera, A.G.; Herrera-Viedma, E.; and Herrera, F. (2011). "An approach for detecting, quantifying, and visualizing the evolution of a research field: a practical application to the fuzzy sets theory field", Journal of Informetrics, Vol. 5 No. 1, pp.146-166. https:// doi.org/10.1016/j.joi.2010.10.002.

14. Hosseini, M.R.; Martek, I.; Zavadskas, E.K.; Aibinu, A.A.; Arashpour, M.; and Chileshe, N. (2018). "Critical evaluation of off-site construction research: a scientometric analysis", Automation in Construction, Vol. 87, pp.235-247. https://doi.org/10.1016/j.autcon.2017.12.002.

15. Van Eck, N.J. and Waltman, L. (2014). "Visualizing bibliometric networks", in: Y. Ding, R. Rousseau, \& D. Wolfram (Eds.), Measuring Scholarly Impact: Methods and Practice, Springer, Cham, pp. 285-320. http://dx.doi.org/10.1007/978-3-319-10377-8 13.

16. Natephra, W., Yabuki, N., and Fukuda, T. (2018). Optimizing the evaluation of building envelope design for thermal performance using a BIM-based overall thermal transfer value calculation. Building and Environment, 136, 128-145. doi:10.1016/j.buildenv.2018.03.032.

17. Parra, J., Pérez-Pons, M., and González, J. (2021). Technology as a lever for the evolution and recovery of the financial and construction sectors in Spain doi:10.1007/9783-030-53829-3 17.

18. Khairulzaman, H. A., and Usman, F. (2018). Automation in civil engineering design in assessing building energy 
efficiency. International Journal of Engineering and Technology, 7(4), 722-727. doi:10.14419/ijet.v7i4.35.2309.

19. Bruno S, Fino M D, Fatiguso F (2018) Automation in Construction Historic Building Information Modelling: performance assessment for diagnosis-aided information modelling and management. Automation in Construction. 86, December 2017, 256-276 DOI: 10.1016/j.autcon.2017.11.009.

20. Chen K, Lu W, Peng Y, Rowlinson S, Huang G Q (2015) Bridging BIM and building: From a literature review to an integrated conceptual framework. International Journal of Project Management. 33, 6, 1405-1416 DOI: 10.1016/j.ijproman.2015.03.006

21. Golparvar-Fard M, Peña-Mora F, Savarese S (2015) Automated Progress Monitoring Using Unordered Daily Construction Photographs and IFC-Based Building Information Models. Journal of Computing in Civil Engineering. 29, 1 DOI: 10.1061/(ASCE)CP.19435487.0000205 .

22. Huang Y, Huang K, Wang L, Tao D, Tan T, Li X (2008) Enhanced biologically inspired model. IEEE Conference on Computer Vision and Pattern Recognition. DOI: 10.1109/CVPR.2008.4587599.

23. Jalaei F, Canada C, Jrade A (2015) Integrating decision support system (DSS) and building information modeling (BIM) to optimize the selection of sustainable building components Journal of Information Technology in Construction, 20, 399-420 DOI: itcon.org/2015/25.

24. In J, Kim J, Fischer M, Orr R (2015) Automation in Construction BIM-based decision-support method for master planning of sustainable large-scale developments.
Automation in Construction, 58, 95-108 DOI: 10.1016/j.autcon.2015.07.003.

25. Liu R, Yang B, Zio E, Chen X (2018) Artificial intelligence for fault diagnosis of rotating machinery: A review. Mechanical Systems and Signal Processing, 108, 33-47 DOI: 10.1016/j.ymssp.2018.02.016.

26. Memon A H, Rahman I A, Memon I, Azman N I A (2014) BIM in Malaysian Construction Industry: Status, Advantages, Barriers and Strategies to Enhance the Implementation Level. Research Journal of Applied Sciences, Engineering and Technology, 606-614 DOI: airitilibrary.com/Publication/alDetailedMesh?docid=204074 67-201408-201502170022-201502170022-606-614.

27. Teizer J (2015) Status quo and open challenges in visionbased sensing and tracking of temporary resources on infrastructure construction sites. Advanced Engineering Informatics, 29, 2, 225-238 DOI: 10.1016/j.aei.2015.03.006.

28. Tixier A J, Hallowell M R, Rajagopalan B, Bowman D (2016) Automation in Construction Application of machine learning to construction injury prediction. Automation in Construction, $\quad 69, \quad 102-114 \quad$ DOI: 10.1016/j.autcon.2016.05.016.

29. Woo J, Menassa C (2014) Virtual Retrofit Model for aging commercial buildings in a smart grid environment. Energy and Buildings, 80, 424-435 DOI: 10.1016/j.enbuild.2014.05.004

30. Zhang J, El-gohary, N M (2017) Automation in Construction Integrating semantic NLP and logic reasoning into a unified system for fully-automated code checking. Automation in Construction, 73, 45-57 DOI: 10.1016/j.autcon.2016.08.027. 